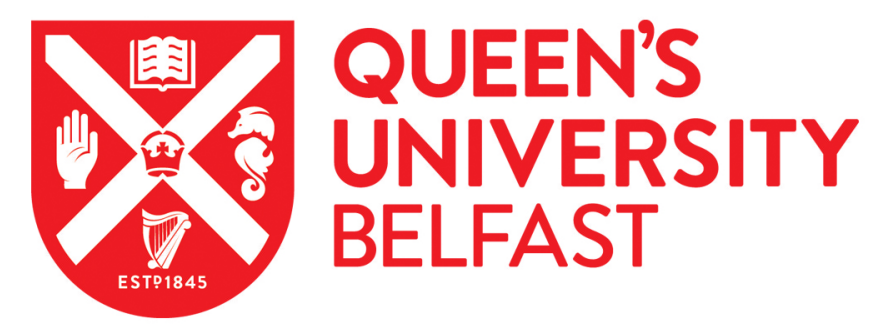

\title{
Per Unit Displacement of Synchronous Inertia With BESS Synthetic Inertia Devices
}

Brogan, P. V., Best, R., Morrow, D. J., Alikhanzadeh, A., \& Kubik, M. (2018). Per Unit Displacement of Synchronous Inertia With BESS Synthetic Inertia Devices. In 2018 IEEE Power \& Energy Society General Meeting (PESGM): Proceedings (IEEE Power \& Energy Society General Meeting (PESGM): Proceedings). https://doi.org/10.1109/PESGM.2018.8586323

Published in:

2018 IEEE Power \& Energy Society General Meeting (PESGM): Proceedings

Document Version:

Peer reviewed version

Queen's University Belfast - Research Portal:

Link to publication record in Queen's University Belfast Research Portal

Publisher rights

(C) 2018 IEEE.

This work is made available online in accordance with the publisher's policies. Please refer to any applicable terms of use of the publisher.

\section{General rights}

Copyright for the publications made accessible via the Queen's University Belfast Research Portal is retained by the author(s) and / or other copyright owners and it is a condition of accessing these publications that users recognise and abide by the legal requirements associated with these rights.

Take down policy

The Research Portal is Queen's institutional repository that provides access to Queen's research output. Every effort has been made to ensure that content in the Research Portal does not infringe any person's rights, or applicable UK laws. If you discover content in the Research Portal that you believe breaches copyright or violates any law, please contact openaccess@qub.ac.uk. 


\section{Per Unit Displacement of Synchronous Inertia With BESS Synthetic Inertia Devices}

\author{
Paul V. Brogan, Robert Best, \\ D. John Morrow, Amir Alikhanzadeh \\ School of Electronic, Electrical Engineering and Computer Science \\ Queens University Belfast, UK \\ paul.brogan@qub.ac.uk
}

\author{
Marek Kubik \\ Market Director \\ AES Energy Storage \\ Amsterdam, Netherlands
}

\begin{abstract}
Synthetic inertia offers the potential to increase power system stability during generation-load imbalances; particularly when conventional generation has been displaced by non-synchronous in-feed. This study is based on three frequency transients caused by the loss of $14 \%$ of the synchronous generation on the Irish system. Analysis of PMU data from power plants is used to determine the per unit displacement potential with BESS of differing delay times and ramp rates. It is observed that synchronous generators undergo a step change in power output during frequency transients. The unsuitability of a droop response for a synthetic inertia response is demonstrated and that a step change in power output is required to maximize inertial participation. The displacement results are compared to existing and proposed operating characteristics of the Irish system.
\end{abstract}

\section{INTRODUCTION}

As the penetration of inverter based distributed generation (DG) becomes appreciable (Ireland regularly operates above $50 \%$ ), concerns regarding low power system inertia become a limiting factor on renewable energy utilization [1]. On a typical power system, a change in electrical frequency is tied to a change in the angular velocity of generators and motors connected to the system. Power system inertia opposes change in power system frequency, limiting the rate-of-change-offrequency (RoCoF).

The severity of a frequency transient can be summarized with the maximum recorded $\mathrm{RoCoF}$ and maximum frequency deviation, following a sudden loss or gain of generation. As system inertia decreases the severity of a frequency transient will increase for a given change in power. The resistance to change provided by system inertia allows time for generation plant control and actuation systems to provide reserve and restore system frequency.

A danger posed by a severe frequency transient is cascade tripping of DG. It is vital that DG devices disconnect from the power system if their section of network is separated (islanded) from the main network [2]. On the Irish system these relays were activated if a RoCoF exceeding $500 \mathrm{mHz} / \mathrm{s}$ was observed over a window of $500 \mathrm{~ms}$; this is being increased to $1 \mathrm{~Hz} / \mathrm{s}$ due to the uncertainty introduced by DG [3].

The events studied in this paper resulted in RoCoF in the region of $350 \mathrm{mHz} / \mathrm{s}$; following the unscheduled loss of a unit

This work was supported by Innovate UK and EPSRC under Grant EP/N508408/1. providing $14 \%$ of synchronous generation and $11 \%$ of demand. In the short term operational limits can be increased, but it is in everyones interest to limit RoCoF on power systems, especially those expanding non-synchronous infeed.

Inverter based technology can import and export power independent of frequency. The displacement of synchronous generation, by DG such as photovoltaics and wind, has a signicant effect on system response to frequency change. The Irish power system currently limits system non-synchronous penetration (SNSP) to $60 \%$, the goal is to increase this to $75 \%$ by 2020 [4]. At present system inertia is maintained by keeping plant synchronized at reduced output, increasing cost, emissions and renewable generation curtailment.

The fact that power electronics can act independently of frequency and can change their import export characteristics quickly means they have the potential to emulate the inertial response of conventional generators. At present some TSOs are in the process of tendering for services that cover inertial and enhanced frequency responses [5], [6]. This paper demonstrates the extent to which synthetic inertia devices can replace energy delivery from synchronous sources.

This investigation is primarily based on the response of the majority of Ireland's combined cycle gas turbines (CCGT) during the transient events. The units were monitored by phasor measurement units (PMU) allowing their power and energy response to be accurately quantified. The power and energy response from potential BESS devices is easily calculated and this response compared to the observed synchronous response.

It is concluded from the analysis of PMU data that the existing power system response, to a signicant frequency transient, is a step change in power delivery [7]. It is proposed that synthetic inertia devices mimic the step change to achieve greatest power response and energy delivery. If an emergency ramp is initiated then there appears to be an 8 to 1 displacement potential of CCGT inertial response by BESS response, if a combined delay time and ramp time of $100 \mathrm{~ms}$ can be achieved.

It is the aim of this research to demonstrate that an effective synthetic inertia response is predicated on an aggressive ramp response and a rapid transient detection method. The secondary aim is to encourage TSOs to set requirements for the displacement of synchronous inertia. 


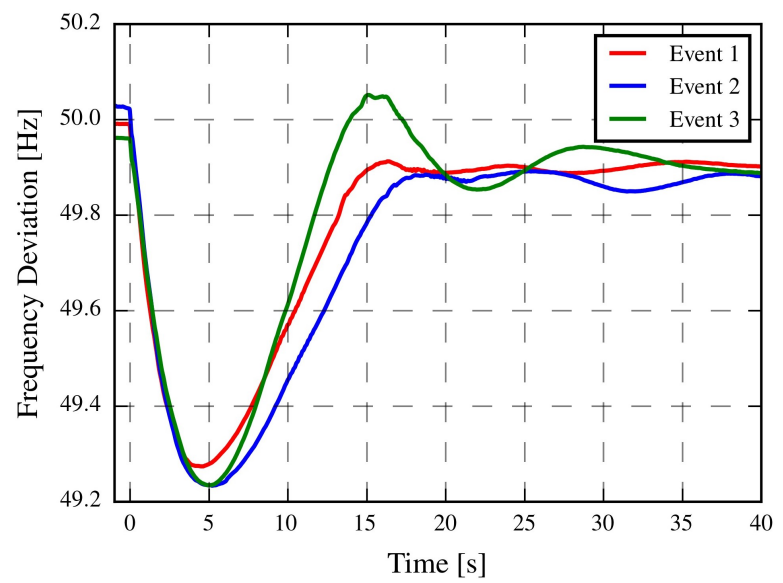

Fig. 1. Plot of Frequency Transients resulting from loss of $430 \mathrm{MW}$ generator

\section{TRANSIENTS AND RESPONSE ON THE IRISH SySTEM}

Displayed in Fig 1 is a plot of the frequency transients that resulted from the loss of generation detailed in Table I. The events are characteristic of frequency transients observed on relatively small and responsive systems (Irelands peak demand is approximately $6 \mathrm{GW}$ ). Typically, the control systems and power system reserve will return the frequency on the Irish system to nominal within 20 seconds.

Despite the similarity between the frequency plots, there were appreciable differences between the grid conditions. The transients all occurred in the second quarter of 2016, but at different times of the day, so the demand varies by $17 \%$. The fuel mix also varies appreciably between 430 and 1,050 MW from non-synchronous sources (Table I, SNSP); as well as between gas and coal generation, varying from 1.4:1 to 3:1.

It can be observed from Table 1 that synchronous generation remains remarkably constant between the events. It is hypothesized that synchronous generation, along with generation loss, has the greatest effect on the transient characteristic. It is for this reason that synchronous plant is constrained on, in the Irish system and the largest single infeed may be reduced on the British system [6]. While these constraints improve security they increase cost and emissions.

\section{A. Response of Generation to the Transients}

Over the three events between $47 \%$ and $56 \%$ of total generation was being monitored by PMU and recorded by EirGrid/SONI, it is this data used in the paper.

The large number of frequency and $\mathrm{RoCoF}$ measurements available from these PMUs allows for a very accurate and noise reduced estimate of global conditions. The metering of many units also allows for a general perception of how different generation technologies respond. In this study CCGT displacement is focused on as this is the primary source of electrical power on the Irish system and between 67\% and $92 \%$ of total CCGT generation was recorded.

Shown in Fig 2 is the estimated total response from all generators operating on the power system, they are grouped

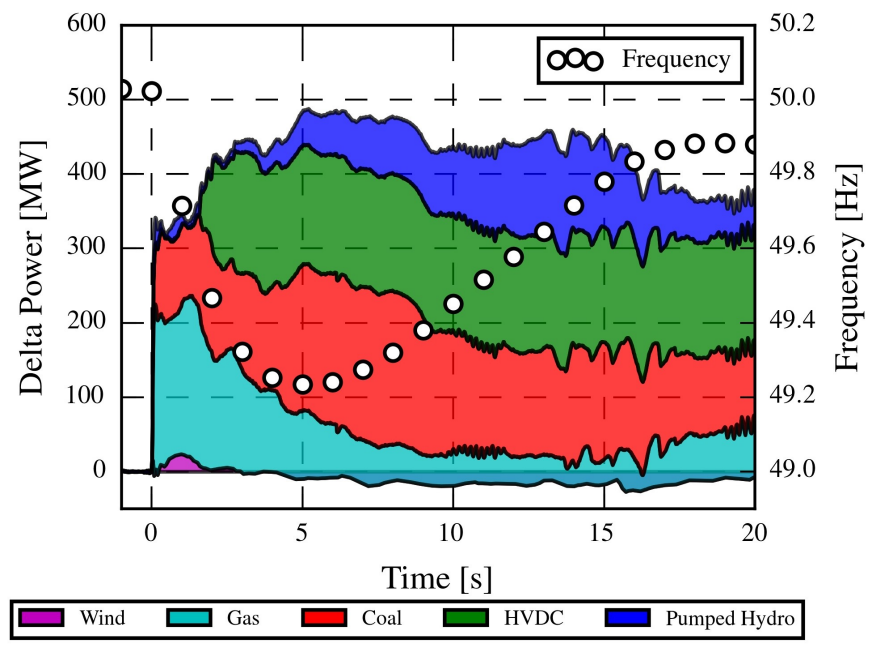

Fig. 2. Response of generators to frequency transient

TABLE I

DETAILS OF THE FREQUENCY TRANSIENTS STUDIED

\begin{tabular}{cccc}
\hline Event Label & E1 & E2 & E3 \\
\hline Total Demand [MW] & 3490 & 3943 & 4087 \\
Gen Loss [MW ] & 433 & 432 & 437 \\
\% of Total Sync. Gen. & 14.2 & 13.5 & 14.4 \\
SNSP [\%] & 13.0 & 20.7 & 30.2 \\
Frequency Nadir [Hz] & 49.27 & 49.23 & 49.23 \\
Time of Freq. Nadir [s] & 4.58 & 5.26 & 4.96 \\
\hline
\end{tabular}

by fuel. The PMU measured response of the generators is scaled up by the publicly available generation mix [8] at the time of the frequency transient. It can be observed that,

- Wind has a negligible inertial response

- Gas a high inertial and small droop response

- Coal a medium inertial and high droop response

- HVDC provides a large static reserve response

- Pumped hydro has little beneficial effect

It is noteworthy that the synchronous generators respond with a step response in power delivery at the beginning of the transient. This power ramp is on the order of $7.5 \mathrm{GW} / \mathrm{s}$ over $40 \mathrm{~ms}$. The initial power ramp, followed by the plateau, is driven by the initial high stable RoCoF. As RoCoF reduces the inertial response falls from CCGT, but is replaced by the HVDC static reserve and the droop response from coal.

Synthetic inertia offers the possibility of effectively implementing the HVDC response within tens or hundreds of milliseconds after the transient onset, not seconds after. Such a response can be termed synthetic inertia as it actively reduces $\mathrm{RoCoF}$ and consequently greatly improves the frequency nadir.

\section{B. Ideal BESS Response}

At present QUB are working with EirGrid/SONI and AES to monitor the performance of a 10 MW BESS at Kilroot Power Station, Northern Ireland. The BESS is contracted to follow a droop characteristic and its old operational characteristic is 


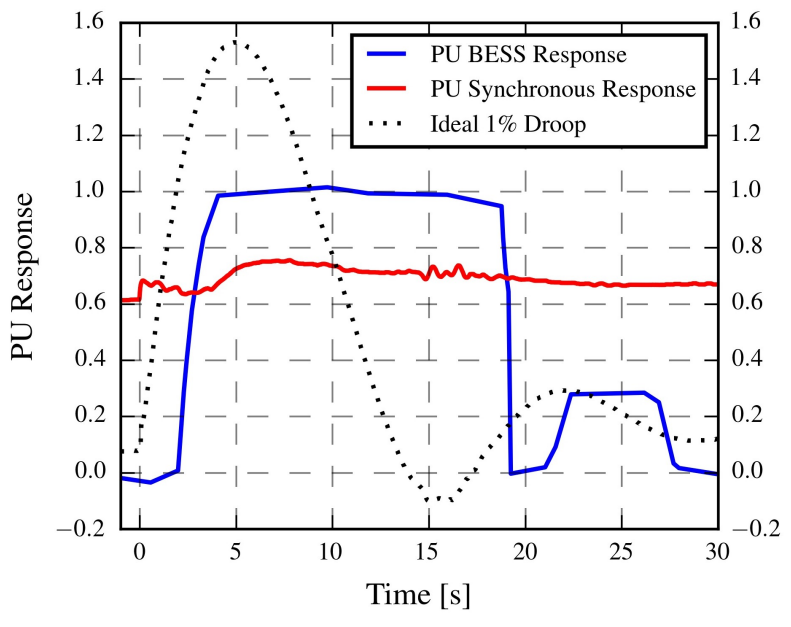

Fig. 3. Per Unit Response of BESS and Synchronous Machine

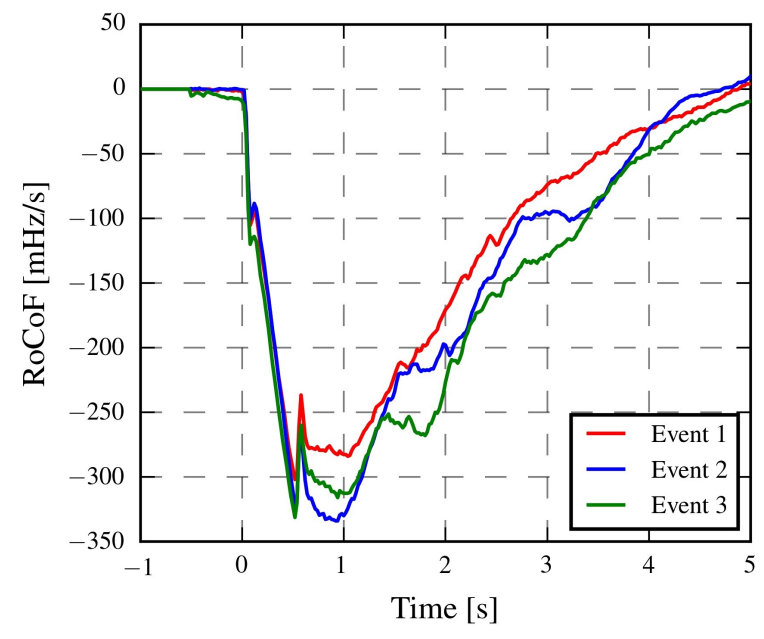

Fig. 4. RoCoF Observed during three events

shown in Fig 3, compared against an on-site coal unit. At the time of this event the unit was operating at a $1 \%$ droop and was required to respond within 5 seconds; as part of this demonstration project the response time has been reduced to the order of $100 \mathrm{~ms}$.

It can easily be concluded that a droop characteristic is wholly unsuited for RoCoF reduction in this environment. Typically, the frequency needs to fall outside a deadband (e.g. $49.9 \mathrm{~Hz}$ ) before any response is initiated; even at a RoCoF of $1 \mathrm{~Hz} / \mathrm{s}$ it will take on average $100 \mathrm{~ms}$ to reach the deadband. Once a $1 \%$ droop response was initiated it would take a further $500 \mathrm{~ms}$ to reach maximum output. Only in this extreme condition and with zero latency would a droop response start to approach the responses proposed in Section III.

Shown in Fig 4 is the RoCoF that would be measured by an anti-islanding relay (e.g. G59 [2]) averaging over $500 \mathrm{~ms}$. The first notable point occurs $500 \mathrm{~ms}$ after the beginning of the fault, this is apparent in the sharp minimum. The second notable point is around the 1 second mark when a second minimum is reached, though the severity of this was variable.

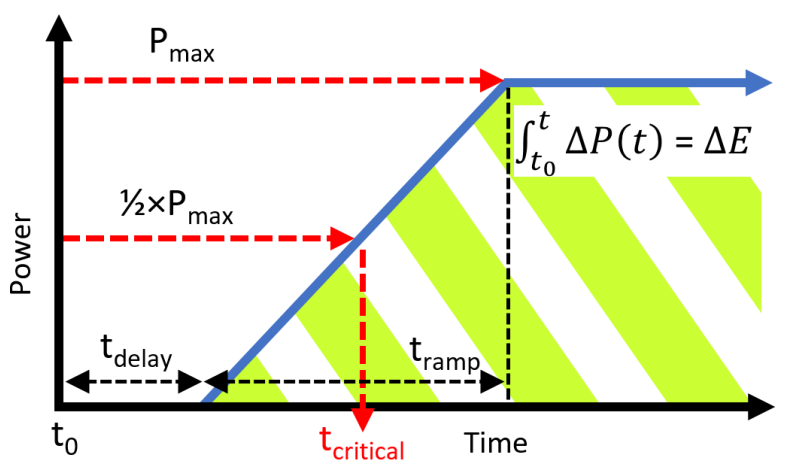

Fig. 5. Per Unit Response of BESS and Synchronous Machine

For a BESS to achieve half its potential to reduce RoCoF on the Irish power system, it must be delivering half its rated power by $250 \mathrm{~ms}$ (assuming a linear power ramp Fig 5). If this criterion is achieved then the BESS will subsequently be making substantial contributions to reducing $\mathrm{RoCoF}$ at the 1 second mark and help to improve the frequency nadir. In all cases the effectiveness of the unit at ameliorating the grid issues is quantified with the additional energy delivered to the system between the start of the event and the relevant time.

A striking feature to note from Fig 3 is the difference in the per unit inertial response from a synchronous generator ( 7 to $14 \%$ during this transient) and the potential per unit response of a BESS. In some ways, the comparison is unfair as the BESS is a service provider while the generator provides power; but when synchronous generators start to be paid for their inertial service [5] the comparison becomes more apt.

The displacement factor of synchronous inertia by synthetic inertia can then be determined by dividing synthetic inertia energy delivery by synchronous inertia energy delivery.

\section{Modeled BESS Response}

The model of the BESS response is shown in Fig 5, this consists of a delay time followed by a linear ramp. This type of response may appear quite artificial, however it attempts to accurately reproduce the addition of an ideal per unit inertial response and an ideal per unit droop response. This type of response is vitally necessary for maximum power delivery in minimum time. EirGrid/SONI, Irelands TSOs, released [9] in which various BESS responses were considered, including a step response, with droop ramp off.

Power system engineers are cautious when it comes to introducing a step change into power systems, as it can introduce undesirable harmonics and sub-synchronous oscillations. It can be observed from Fig 2 that synchronous machines undergo a much more drastic power ramp than can realistically be achieved by inverters in the near term. Subsequent to this the HVDC static reserve response is initiated as a ramped step change with only beneficial consequences. If synthetic inertia operation is found to be too aggressive it can always be moderated by reducing the ramp rate. 


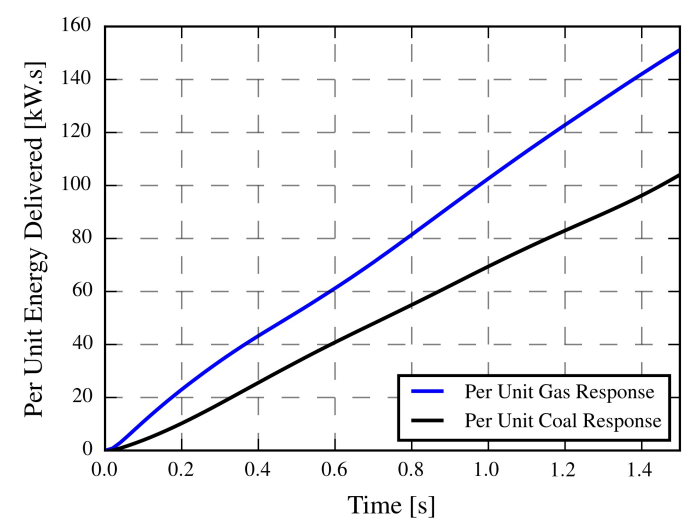

Fig. 6. Per unit energy response of synchronous plant to frequency transient

In modeling the ideal BESS response two times are initially important, the delay time $\left(t_{\text {delay }}\right)$ and the ramp time $\left(t_{\text {ramp }}\right)$, Fig 5. The delay time arises from the time taken to identify that a loss of generation has occurred and instruct the inverter to undergo an emergency ramp response. The ramp time is the time required to increase output from zero to maximum power output. BESS with varying delay times and ramp times may be functionally identical if their critical times $\left(t_{\text {critical }}\right)$ are the same. For a linear ramp the critical time will be the delay time plus half the ramp time. BESS units with differing delay and ramp times will deliver the same energy to the grid after they have reached maximum power $\left(P_{\max }\right)$.

The BESS installed at Kilroot Power Station by AES has demonstrated power responses with delay times on the order of $100 \mathrm{~ms}$. Ramp times on the order of $300 \mathrm{~ms}$ have been observed, but these have not been optimized for strict ramping and AES are confident that this can be reduced to less than 100 ms. At present the BESS in participating in the fast frequency response service [5], but the array should have the potential to achieve a critical time of $150 \mathrm{~ms}$ or less.

\section{Per Unit Synchronous Inertia Displacement}

Shown in Section II, Fig 2 was the power response of CCGT and coal plant to a loss of generation event; if this power response is divided by the MW capacity of the connected units then a per unit inertial power response from the generators can be calculated. Shown in Fig 6 is the per unit energy delivered by coal and gas synchronous machines; this is simply the integral of the per unit power response. Event 1 was chosen for this analysis as the CCGT and coal plant had the best inertial response. It can be observed that the additional energy delivered to the grid rises fairly linearly, starting from the origin of the plot.

Shown in Fig 7 is the amount of energy that would be delivered to the power system by BESS with varying critical times. A BESS with a critical time of $50 \mathrm{~ms}$ (e.g. 40ms delay, $20 \mathrm{~ms}$ ramp) is aspirational but possible, one with a critical time of $75 \mathrm{~ms}$ (e.g. $50 \mathrm{~ms}$ delay, $50 \mathrm{~ms}$ ramp) should be realizable in the near term, a critical time of $150 \mathrm{~ms}$ (e.g. 100 ms delay and $100 \mathrm{~ms}$ ramp) could be implemented on the AES

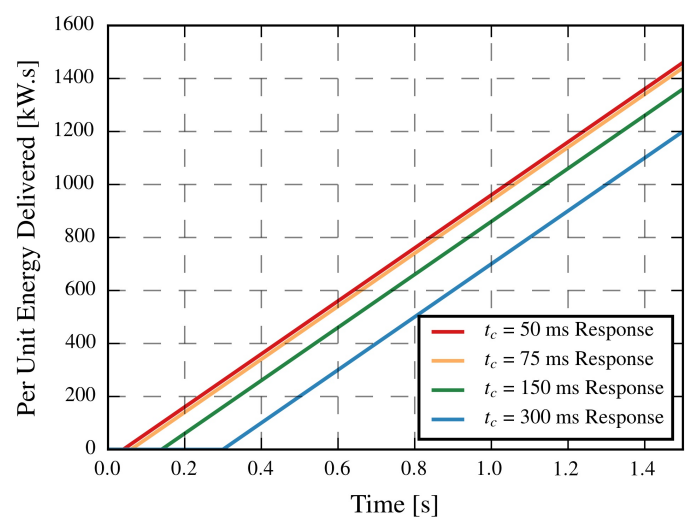

Fig. 7. Per unit energy response from BESS devices with varying critical times $\left(t_{c}=\right.$ DelayTime $+1 / 2 \times$ RampTime)

unit at Kilroot Power Station, while a BESS with a critical time of $300 \mathrm{~ms}$ ( $200 \mathrm{~ms}$ delay and $200 \mathrm{~ms}$ ramp) should be easily implemented and still has an appreciable displacement factor, as demonstrated in the results.

The plots in Fig 7 show the per unit energy delivery that would be achieved by BESS units with the specified critical time. The plots are linear and have a gradient of 1, as the BESS can quickly reach a full per unit response (provided it was not exporting power previous to the fault). The lines intercept the $\mathrm{x}$-axis at their critical time, as this is when full power export begins in the study. BESS with the same critical time, but differing delay and ramp times, will deliver essentially the same power over the intervals considered $(500 \mathrm{~ms}$ and $1 \mathrm{~s})$. It is noteworthy that the y-axis scale in Fig 7 is ten times larger than the scale in Fig 6.

\section{A. Results}

Fig 8 is a plot of the per unit synthetic inertial energy delivery of varying BESS units, divided by the per unit energy delivery of CCGT plant. In this study, CCGT plant was observed to have the most robust inertial response and as the response of many units was averaged the results are widely applicable. It is the intention of synthetic inertia to replace the inertial response of synchronous plant, meaning fewer plant are constrained on for network services. This is a necessary condition to meet Ireland's ambitious renewable energy target target of $40 \%$ of electrical energy coming from renewable sources by 2020 [10] and in wider E.U. policy [11].

It can be observed in Fig 8 that displacement of synchronous response does not begin until the BESS activates at the critical time; a subject of future research will be the value of energy delivery before this point. Once the critical time is reached energy delivery from BESS increases quickly and rapidly surpasses unity displacement. After 1 second $1 \mathrm{MW}$ of CCGT plant had delivered on average 0.102 MW.s, (this can be inferred from Fig 6); this is $10.2 \%$ of the maximum potential, consequently a maximum per unit displacement of 9.80 can be achieved over the first one second. It can be noted from Fig 8 that the plots tend towards 9.8 as critical time decreases. 


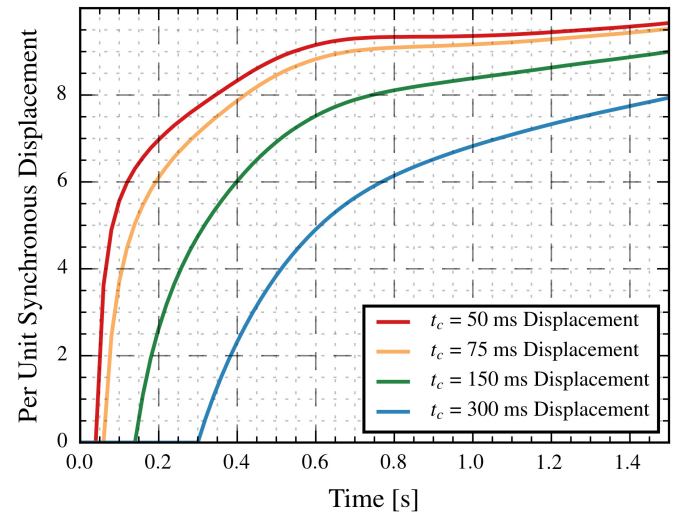

Fig. 8. Per unit displacement of synchronous inertia energy response (from CCGT plant) by BESS synthetic inertia energy response

A critical displacement factor for the Irish system is 1:8.33 (BESS:Synchronous Plant), as Irelands TSO has proposed in [9] that $360 \mathrm{MW}$ of BESS should provide sufficient stability to operate at an SNSP of $75 \%$. At a displacement ratio of 1:8.33 $360 \mathrm{MW}$ of synthetic inertia response could replace the inertial response of $3 \mathrm{GW}$ of CCGT. If $25 \%$ of demand is met by synchronous generation, then the power system should have a stability exceeding a synchronized unit capacity of $4 \mathrm{GW}$. It can be deduced from the publicly available data at [8] that since 2008 the Irish power system has spent $19.0 \%$ of its time operating with less than $4 \mathrm{GW}$ of synchronized generation online.

As mentioned previously the first maximum RoCoF recorded by anti-islanding relays (operating with a $500 \mathrm{~ms}$ window) will occur $500 \mathrm{~ms}$ after the onset of the event. It can be observed from Fig 8 that a displacement ratio of 1:8.5 is achieved after $500 \mathrm{~ms}$ by BESS with a critical time of less than $75 \mathrm{~ms}$ (realizable with next generation technology). It is noteworthy that BESS with a critical time of $150 \mathrm{~ms}$ (realizable with existing technology) can have a displacement of almost 1:7 and at $300 \mathrm{~ms}$ a displacement of 1:3.8 is achieved in the 0 to $500 \mathrm{~ms}$ region.

If $360 \mathrm{MW}$ of BESS was operating with a delay time in the region of $150 \mathrm{~ms}$ then they could deliver the equivalent energy as a minimum of $2.5 \mathrm{GW}$ of synchronous generation by $500 \mathrm{~ms}$. At an SNSP of $75 \%$ a minimum stability of 3.3 GW synchronized generation would be achieved; since 2008 Ireland has spent $2.7 \%$ of the time operating below this point. If units were part loaded at $70 \%$ then the stability would be increased to $3.6 \mathrm{GW}$, Ireland has spent $8.7 \%$ of the time below this stability point.

On larger, less dynamic, systems the energy delivered by $500 \mathrm{~ms}$ post event may be of less consequence than energy delivered by 1 second. It can be observed from Fig 8 that the displacement ratio of BESS with response times of less than $150 \mathrm{~ms}$ are converging to a figure of between 1:8.4 to 1:9.4. Even a BESS with a slow response of $300 \mathrm{~ms}$ has a significant displacement factor nearing 1:6.8 after 1 second.

\section{Conclusion}

BESS present a major opportunity for making the power system more secure against sudden changes in generation and demand. In this investigation the first 1 second post fault has been considered as it is during this time that the largest RoCoF is observed. The danger is that a large RoCoF can cause tripping of distributed generation, along with damage to plant and subsequently load shedding, if frequency drops too low.

In this investigation it is demonstrated that a rapid BESS response is required for significant reduction in RoCoF. Ideally the BESS will respond in less than $150 \mathrm{~ms}$ (realizable with the current BESS at Kilroot Power Station, AES), though significant gains can be realized with a response time of less than $300 \mathrm{~ms}$. The optimal method of achieving this displacement is via a step/ramp in power (triggered by an emergency response), this mimics the existing power system inertial response.

Irelands TSO has proposed that $360 \mathrm{MW}$ of BESS would provide sufficient services to allow the Irish power system to securely operate at a non-synchronous penetration of $75 \%$. This investigation concludes that good stability would be achieved by BESS with response times in the region of $75 \mathrm{~ms}$, but acceptable stability could be achieved with response times of $150 \mathrm{~ms}$ if synchronous units are part loaded at $70 \%$.

Smaller systems, such as Ireland and Great Britain, will likely benefit more from rapid BESS response than continental power systems. But the demonstration of rapid flexible response from BESS should demonstrate its utility for applications, particularly on vulnerable sections of network on larger systems.

\section{ACKNOWLEDGMENT}

The authors would like to thank AES Energy Storage, AES UK \& Ireland, Eirgrid/SONI, The Northern Ireland Utility Regulator, and Northern Ireland Electricity for their valuable input and Innovate UK for their financial support.

\section{REFERENCES}

[1] Ulbig, Andreas and Borsche, Theodor S and Andersson, Göran Impact of low rotational inertia on power system stability and operation. IFAC Proceedings Volumes, vol. 47, no. 3, pp. 7290-7297, 2014

[2] Heggie, G and Yip, HT A multi-function relay for loss of mains protection, IET, 1998

[3] EirGrid, SONI DS3: RoCoF Workstream Plan 2015, 2015

[4] EirGrid DS3 Programme Operational Capability Outlook 2016, May 2016

[5] EirGrid/SONI DS3 System Services Interim Tariff Rates, August, 2016

[6] National Grid System Needs and Product Strategy, June, 2017

[7] P.V. Brogan , A.H. Alikhanzadeh, R. J. Best, D. J. Morrow , M. L. Kubik Fast Frequency Response Requirements for Replacement of Observed Generator Response During Under Frequency Transients. cigré Symposium Dublin May 2016

[8] SEMO (Ireland) Single Electricity Market Operator, www.sem-o.com October, 2017

[9] EirGrid/SONI RoCoF Alternative \& Complementary Solutions Project Phase 2 Study Report, March, 2016

[10] seai, Sustainable Energy Authority of Ireland Renewable Electricity in Ireland 2015. 2016 Report

[11] European Commission 2020 climate \& energy package, https://ec. europa.eu/clima/policies/strategies/2020_en, October, 2017 